\title{
Students' Perceptions and Attitudes After Exposure to Three Different Instructional Strategies in Applied Anatomy
}

\author{
Khalid A Bin Abdulrahman (D) \\ Mohammad I Jumaa ${ }^{2,3}$ \\ Safaa M Hanafy ${ }^{2}$ \\ Eman A Elkordy ${ }^{2}$ \\ Mostafa A Arafa ${ }^{4,5}$ \\ Tauseef Ahmad (iD ${ }^{6}$ \\ Shahzad Rasheed ${ }^{2}$ \\ 'Department of Medical Education, \\ ${ }^{2}$ Anatomy Department, College of \\ Medicine, Imam Mohammad Ibn Saud \\ Islamic University (IMSIU), Riyadh, Saudi \\ Arabia; ${ }^{3}$ College of Medicine, Al-Azhar \\ University, Assiut, Egypt; ${ }^{4}$ The Cancer \\ Research Chair, College of Medicine, \\ King Saud University, Riyadh, Saudi \\ Arabia; ${ }^{5}$ High Institute of Public Health, \\ Alexandria University, Alexandria, Egypt; \\ ${ }^{6}$ Department of Medical Education, \\ College of Medicine, King Saud \\ University, Riyadh, Saudi Arabia
}

Background: The advancements of technologies have developed anatomical education into a new era. The study aims to assess medical students' performance and overall satisfaction who used the anatomage table and plastinated specimens for the teaching and learning anatomy courses.

Methods: A cross-sectional study was conducted on students of the first-year college of medicine at Imam Mohammad Ibn Saud Islamic University (IMSIU). Students were randomly distributed equally into three groups A, B, and C. All groups were taken two sessions of lectures for one hour each. Each lecture was followed by a practical session of two hours. Group A learned with the "Anatomage" table and Group B learned the same topics on plastinated specimens. Group C was learning on both plastinated specimens and the "Anatomage" table. The objective structured practical examination was given to all students immediately after the practical sessions. A structured questionnaire was given to each group to determine the students' views on the educational methods.

Results: There was a statistically significant difference between the means of the total scale scores for the three teaching methods, where students expressed a higher attitude towards both strategies for teaching in comparison to the anatomage table and plastinated models for teaching, where the means were $18 \pm 4.4,18.3 \pm 4.6,20.4 \pm 5.6$, respectively, $\mathrm{F}=12.6$ and $\mathrm{P}=0.0001$. There were higher and positive students' attitudes regarding the five statements in favor of both models teaching compared to anatomage table and plastinated model teaching alone.

Conclusion: The first-year medical students have valued the combination of anatomage table and plastinated prosections in learning and assessing anatomy education at the undergraduate level. The advantages outweigh the limitation of these educational tools.

Keywords: anatomy education, anatomage, plastinated prosections, medical education, Saudi Arabia

\section{Introduction}

The science of human anatomy typically focuses on studies the human body structures at various levels, macro, micro, and developmental. ${ }^{1}$ Undoubtedly, anatomy is a cornerstone of basic science medical education for medical students worldwide. ${ }^{2}$ All medical students must learn gross anatomy, histology, and embryology; these are essential medical and applied health basic sciences. ${ }^{1,3}$ The foundation of anatomy education prepares the students for clinical education and future practice of medicine. ${ }^{4}$ Most medical and health sciences schools use different modern educational strategies in teaching and learning anatomy for
Correspondence: Khalid A Bin

Abdulrahman

Department of Medical Education,

College of Medicine, Imam Mohammad

Ibn Saud Islamic University (IMSIU),

Riyadh, Saudi Arabia

Email kab@imamu.edu.sa 
their undergraduate students. Technology has recently played essential roles in developing education in anatomy. ${ }^{5,6}$ Cadavers are indispensable tools that students and educators have used for teaching anatomy since the Renaissance. ${ }^{7}$ The method of formaldehyde fixation usually preserves cadavers. However, there are some disadvantages to the process of fixation by Formaldehyde. The US Environmental Protection Agency (EPA) and the International Agency for Research on Cancer (IARC) had classified Formaldehyde as a probable human carcinogen. ${ }^{8,9}$ Health education institutions face many challenges and difficulties associated with providing cadavers for educational purposes. Among the most prominent of these challenges are legal, administrative, cultural, religious, social, economic, and educational issues. Therefore, there were efforts to overcome these obstacles by finding technical and computer alternatives to develop anatomical education. ${ }^{10}$ Anatomical plastination is a wellknown, relatively new technique to preserve body or body parts. In plastination, water and fat are substituted by special plastics that lead to unique specimens that can be touched, odorless, decompose, and even maintain most original parts. ${ }^{11}$ Some programs have found plastination specimens similarly applicable to dissection and cadavers management in conveying anatomical lessons. This modality is particularly suitable for a system-based teaching anatomy approach, requiring fewer cadaveric dissection and allowing for similar exposure to information with minimum course time. ${ }^{12}$ With plastination techniques, tissues may be stored for a long time in a non-toxic, dry, durable, and odorless way. ${ }^{13}$ Anatomage Table is a well-developed digital solution designed for anatomy education. ${ }^{14}$ Stereoscopic images have been taken by computerized tomography (C.T.) scan, X-Ray, ultrasound, and magnetic resonance imaging (MRI) of the different human body parts with software to build a 3-dimensional reconstruction of the whole human body. The anatomage technology has been adopted by many of the world's leading medical and health school. ${ }^{15}$ The study aims to enrich academic knowledge with different anatomy teaching methods and measure students' performance and overall satisfaction who used the anatomage table and plastinated specimens; We assumed that the diversity of learning resources more effective and increase students' perception of learning anatomy.

\section{Materials and Methods}

A cross-sectional study, was conducted after approval from the IMSIU IRB committee number 44-2019 dated 2 April 2019. All participated students were informed about the purpose of the study. The urinary system was taken as a topic of learning. Two hundred and eleven students of the first-year college of medicine, IMSIU, have been invited to participate in the study. Students were randomly distributed equally into three groups A, B, and C. All groups were taken two sessions of lectures for one hour each. Each lecture was followed by a practical session of two hours. Regarding the first-year students, Group A learned kidney, ureter, urinary bladder, and urethra with the "anatomage" virtual dissection table during practical hours. Group B learned the same topics on plastinated specimens during the practical session. Group $\mathrm{C}$ was learning the same topics on both plastinated specimens and the "anatomage" virtual dissection table during the practical session. Objective structured practical examination (OSPE) was given to all students immediately after the practical sessions. It was designed and consisted of ten practical questions. All questions were validated for construct validity by faculty members of the anatomy department. Groups (A) were tested with the help of the "Anatomage" virtual dissection table Groups (B) were tested with the use of plastinated specimens. Groups (C) were tested with plastinated specimens and the "Anatomage" virtual dissection table The OSPE was planned for ten marks assigned for practical examination was conducted in three batches, on the same exam day using same questions for each patch but demonstrated according to teaching methods. The OSPE exam consisted of 10 questions of one mark each. The time allotted for each question was 2 minutes. The questions were selected to represent the learning objectives from the first term of the anatomy curriculum. A structured questionnaire was given to each group to determine the students' attitudes on the educational methods. The questionnaire consisted of 15 closed-ended questions. Fifteen questions employed a 5-point Likert-type scale ranging from 5- strongly agree to 1- strongly disagree. The questionnaire was tested in a pilot study on 15 students, where the cronbach's alpha was $90.2 \%$.

\section{Statistical Analysis}

One-way analysis of variance was used to compare the mean values of quantitative variables across the three 
instructional methods. Then the pair means were compared using Duncan's multiple range test. ${ }^{16}$ The analysis was carried out using SPSS PC 17.0 statistical software.

\section{Results}

The total number of students who responded to the questionnaire was 191 (90.2\% response rate). Their age is ranging from 19 to 21 years. Most participants were males $(85 \%)$, and all were in the first-year college of medicine, IMSIU. There was a statistically significant difference between the means of the total scale scores for the three teaching methods, where students expressed a higher attitude towards both strategies for teaching in comparison to the anatomage table and plastinated models for teaching, where the means were $18 \pm 4.4,18.3 \pm 4.6,20.4 \pm 5.6$ respectively, $\mathrm{F}=12.9$ and $\mathrm{P}=0.0001$, Table 1 . Post hoc test (Tukey's) showed that the combined method was significantly different from the other methods. No significant difference was detected between anatomage and plastinated models. No statistically significant difference was detected between the students' final grades regarding the three teaching methods $(\mathrm{F}=1.2$ and $\mathrm{P}=0.3)$, Table 2. Table 3 illustrates students' attitudes and perspectives towards the five statements, across the three teaching methods, after combining the two categories strongly agree and agree together. There were higher and positive students' attitudes regarding the five statements in favor of both models teaching compared to anatomage table and plastinated model teaching alone. No statistical difference was detected regarding the statements related to understanding different body organs' relations and identifications of varying body structures.

\section{Discussion}

Anatomy subject is considering the basic foundation of learning medicine. The teaching of Anatomy plays a vital role in the process of training medical professionals and thereby ensuring safe medical practices. Anatomy remains a core topic for 1st-year medical students. The current study was conducted among first-year medical college

Table I Distribution of the Total Scale Scores' Means Across the Three Teaching Methods

\begin{tabular}{|l|l|l|l|}
\hline Method of Teaching & Mean \pm S.D. & F & P-value \\
\hline Anatomy table & $18 \pm 4.4$ & \multirow{2}{*}{12.9} & $0.000 \mathrm{I}$ \\
\cline { 1 - 2 } Plastinated model & $18 \pm 4.6$ & & \\
\cline { 1 - 2 } Both models & $20.4 \pm 5.6$ & & \\
\hline
\end{tabular}

Table 2 Distribution of the Students' Final Grades Means Across the Three Teaching Methods

\begin{tabular}{|l|l|l|c|}
\hline Method of Teaching & Mean \pm S.D. & F & P-value \\
\cline { 1 - 2 } Anatomy table & $69.58 \pm 16.4$ & \multirow{2}{*}{1.2} & 0.3 \\
\cline { 1 - 2 } Plastinated model & $73.61 \pm 13.8$ & & \\
\cline { 1 - 2 } Both models & $72.94 \pm 18.4$ & & \\
\hline
\end{tabular}

students at Imam Mohammad Ibn Saud Islamic University to assess medical students' performance and overall satisfaction who used the anatomage table and plastinated specimens for the teaching and learning anatomy courses. The present results showed that most students were male (85\%). One of the most critical aspects of new teaching methods development is gender difference. ${ }^{17}$ This result is consistent with Elkordy et al and Bin Eid et al. $^{18,19}$ and disagreed with another study ${ }^{20}$ which reported an equal number of males and females. The current study has shown a statistically significant difference between the three teaching methods' total scale scores. The students expressed a higher attitude towards teaching strategies than the anatomage table and plastinated models for education but did not significantly differentiate between anatomage and plastinated models. This finding supports that the undergraduate students prefer the combination of anatomage and plastinated in teaching and learning anatomy. Results of previous research confirmed that combining multiple teaching methods is the best way to teach modern anatomy. Virtual reality-based computer technology and 3D learning methods are more effective learning anatomy methods than traditional methods. ${ }^{21}$ The finding of another reported study showed that students using online resources to study anatomical material missed the interaction of working in groups around a teaching resource. $^{21}$ Several studies on teaching Human Anatomy ${ }^{22}$ have already compared new teaching methods to traditional ones. Using the technology to enhance medical education is not an alternative for other learning tools but rather a complementary tool to support the educational process. Additionally, several studies demonstrated the medical student's perception toward anatomage table alone or plastination alone. ${ }^{13,20,23,24}$ Still, there have been no studies showing medical students' attitude towards teaching strategies, anatomage table, and plastinated models for education. On the other hand, a previous study indicated that more than $80 \%$ of medical students are satisfied with learning medicine using virtual reality and 
Table 3 Attitudes of Students Towards the Three Teaching Methods

\begin{tabular}{|c|c|c|c|c|c|c|c|}
\hline \multirow[t]{2}{*}{ Statements } & \multicolumn{2}{|c|}{$\begin{array}{l}\text { Anatomage } \\
\text { Table }\end{array}$} & \multicolumn{2}{|c|}{$\begin{array}{l}\text { Plastinated } \\
\text { Models }\end{array}$} & \multicolumn{2}{|c|}{$\begin{array}{l}\text { Both } \\
\text { Models }\end{array}$} & \multirow[t]{2}{*}{ P-value } \\
\hline & No & $\%$ & No & $\%$ & No & $\%$ & \\
\hline Using this teaching method has a Significant benefit in learning outcomes? & 107 & 56 & 117 & 61.3 & 139 & 72.8 & 0.002 \\
\hline Using this teaching method will prepare you to enter a health care profession. & 83 & 43.5 & 116 & 60.7 & 128 & 67 & 0.001 \\
\hline $\begin{array}{l}\text { Using this teaching method gives a better idea about the relations of different body } \\
\text { organs? }\end{array}$ & 123 & 64.4 & 104 & 54.5 & 134 & 70.2 & 0.001 \\
\hline $\begin{array}{l}\text { Using this teaching method in the study of sections in different planes helps better } \\
\text { understand the relations of varying body organs? }\end{array}$ & 112 & 58.6 & 112 & 58.6 & 125 & 65.4 & 0.28 \\
\hline $\begin{array}{l}\text { Using this teaching method facilitates the identification of different structures in the } \\
\text { body? }\end{array}$ & 118 & 61.8 & 110 & 57.6 & 120 & 62.8 & 0.7 \\
\hline
\end{tabular}

anatomage table It is an excellent complement to other methods with several benefits and advantages, but it is not without flaws. ${ }^{25,26}$ Despite the technical improvements in the methods of teaching anatomy, there is still a failure in students' direct learning on the real human organs and tissues. So the best solution is to combine technical and actual means to complement each other. ${ }^{27}$

A comparative study was done between plastinated and cadaveric specimens; the student's feedback to various courses showed the spatial orientation of plastinated specimens than the cadaveric one, but there was no awareness of the plastination technique. ${ }^{13}$ Moreover, the students required more plastinated specimens to understand the complicated structure, such as the arch of the aorta, segmental branch of the renal artery, and bronchial tree. There is no doubt that teaching with multiple techniques is fundamental to make the student understand a vast subject like anatomy. Plastination is a new approach to teach anatomy. It is a technique that allows tissue preservation in a dry, non-toxic, durable and odorless state. It will enable students to have handson experiences in this field without exposure to a chemical such as formalin. ${ }^{13}$ The present results revealed higher and positive students' attitudes regarding the five statements in favor of both models teaching compared to anatomage table and plastinated model teaching methods. The study participants have particularly stated that both anatomage and plastinated models have a significant benefit in learning outcomes, prepare the student to enter a health care profession, and give a better idea about the relations of different body organs with no statistical difference regarding understanding other body organs' relations and identifications of varying body structures. Therefore, the first-year medical student valued anatomage table and plastinated specimens as high-quality anatomy learning tools. The current study has to support the combination of both tools in undergraduate education for better graduation and professional health care.

According to the results of the study, ${ }^{14}$ the anatomage table increases the student's understanding of the internal locations of the human body's organs and the relationships between the various internal structures of the human body. ${ }^{28}$ It also allows the user to view a complete and ideal three-dimensional display of the size, position, and relationships of organs, vessels, nerves, muscles, and spaces inside the human body. Students value learning using the Anatomage Table This is why students believe that the electronic dissection table is a valuable and effective tool in preparing them for medical practice. ${ }^{29,30}$ The present study showed no significant difference between the students' final grades regarding the three teaching methods. The small sample size could explain this particular finding.

\section{Limitation}

The teaching strategies were concise to a limited part in anatomy, making it difficult to explore different teaching methods. The exam question was the same in different teaching methods, even though other teaching methods could have shown their advantages and disadvantages with more detailed and specialized questions. 


\section{Conclusion}

The first-year medical students have valued the combination of anatomage table and plastinated prosections in learning and assessing anatomy education at the undergraduate level. The advantages outweigh the limitation of these educational tools.

\section{Disclosure}

The authors report no conflicts of interest in this work.

\section{References}

1. Nagar SK, Malukar O, Kubavat D, Prajapati V, Ganatra D, Rathwa A. Students' perception on anatomy teaching methodologies. Natl J Med Res. 2012;2(1):111-112.

2. Teunissen PW, Westerman M. Junior doctors caught in the clash: the transition from learning to working explored. Med Edu. 2011;45 (10):968-970. doi:10.1111/j.1365-2923.2011.04052.x

3. Pangaro LN. A shared professional framework for anatomy and clinical clerkships. Clin Anat. 2006;19(5):419-428. doi:10.1002/ ca. 20257

4. Ang E-T, Sugand K, Hartman M, Seow C-S, Bay B-H, Abrahams P. Singapore's anatomical future: Quo Vadis? Anat Sci Educ. 2012;5 (4):234-240. doi:10.1002/ase.1286

5. Fruhstorfer BH, Palmer J, Brydges S, Abrahams PH. The use of plastinated prosections for teaching anatomy-The view of medical students on the value of this learning resource. Clin Anat. 2011;24 (2):246-252. doi:10.1002/ca.21107

6. Narnaware R. Three dimensional (3D) virtual human cadaver, anatomage: an effective teaching tool for human anatomy. FASEB J. 2017;31(S1):lb10. doi:10.1096/fasebj.31.1_supplement.lb10

7. Ghosh SK. Human cadaveric dissection: a historical account from ancient Greece to the modern era. Anat Cell Biol. 2015;48 (3):153-169. doi:10.5115/acb.2015.48.3.153

8. Report to Congress on Indoor Air Quality, Volume II. Assessment and Control of Indoor Air Pollution; 1989. Available from: https:// irp-cdn.multiscreensite.com/c4e267ab/files/uploaded/ kt34RqduTlGgjxf3soeQ_EPA_Report $\% 20$ to $\% 20$ Congress $\% 20$ on $\%$ 20Indoor\%20Air\%20Quality_Volume\%20II_Assessment\%20and\% 20Control\%20of\%20Indoor\%20Air\%20Pollution_1989.pdf. Accessed May 24, 2021

9. Gu Y, Fujimiya Y, Kunugita N. Long-term exposure to gaseous formaldehyde promotes allergen-specific IgE-mediated immune responses in a murine model. Hum Exp Toxicol. 2008;27(1):37-43. doi:10.1177/0960327108088973

10. Challenges in Cadaver availability for learning and research in medical sci. Available from: https://journals.indexcopernicus.com/search/ article?articleId=1444727. Accessed April 26, 2021.

11. Weiglein AH. Overview \& general principles of the plastination procedures; 2011. Available from: https:/web.archive.org/web/ 20110706211411/http://www.uqtr.uquebec.ca/plastination/Abstracts2005.html\#Weiglein-01-2005. Accessed April 26, 2021.

12. Estai M, Bunt S. Best teaching practices in anatomy education: a critical review. Ann Anat. 2016;208:151-157. doi:10.1016/j. aanat.2016.02.010

13. Bhandari K, Acharya S, Srivastava A, Kumari R, Nimmagada HK. Plastination: a new model of teaching anatomy. Int $J$ Anat Res. 2016;4(3.2):2626-2629. doi:10.16965/IJAR.2016.256
14. Martín JG, Mora CD, Henche SA. Possibilities for the use of anatomage (the Anatomical Real Body-Size Table) for teaching and learning anatomy with the students. Biomed J Sci Tech Res. 2018;4 (4). doi:10.26717/BJSTR.2018.04.001094

15. The anatomage table - visualizing life size anatomy - street anatomy. Available from: https://streetanatomy.com/2013/06/13/the-anatomage -table-visualizing-life-size-anatomy/. Accessed April 26, 2021.

16. Metcalfe C. Biostatistics: A Foundation for Analysis in the Health Sciences. 7th ed. Daniel WW, editor. Wiley; 1999:xiv+755+appendices. Price: £28.95. ISBN 0-471-16386-4. Statistics in Medicine. 2001;20(2):324-326. doi:10.1002/1097-0258(20010130)20:2<324:: AID-SIM635>3.0.C.O.;2-O

17. Bleakley A. Gender matters in medical education. Med Educ. 2013;47(1):59-70. doi:10.1111/j.1365-2923.2012.04351.x

18. Elkordy EA, Alsalem AM, Hadal SAN, Bagazi GA, Alkhannani AHA, Alawwad NN. Learning styles and strategies preferences of Imam Mohammed Ibn Saud Islamic University students in gross anatomy courses and their correlations with gender. Int J Med Dev Ctries. 2021;5(2):526-531. doi:10.24911/IJMDC.51-1608130430

19. Bin Eid A, Almutairi M, Alzahrani A, et al. Examining learning styles with gender comparison among medical students of a Saudi University. Adv Med Educ Pract. 2021;12:309-318. doi:10.2147/ AMEP.S295058

20. Alfawzan A, Alfawzan O, Alessa R, et al. An assessment of learning styles among undergraduate medical students at King Saud Bin Abdulaziz University (KSAUHS), King Saud University (KSU) and Imam Mohammad Ibn Saud Islamic University (IMSIU). In Review; 2020. doi:10.21203/rs.3.rs-33877/v1.

21. Triepels CPR, Smeets CFA, Notten KJB, et al. Does three-dimensional anatomy improve student understanding? Clin Anat. 2020;33(1):25-33. doi:10.1002/ca.23405

22. Choudhury B, Gouldsborough I. The use of electronic media to develop transferable skills in science students studying anatomy. Anat Sci Educ. 2012;5(3):125-131. doi:10.1002/ase.1259

23. McMenamin PG, Quayle MR, McHenry CR, Adams JW. The production of anatomical teaching resources using three-dimensional (3D) printing technology. Anat Sci Educ. 2014;7(6):479-486. doi:10.1002/ase.1475

24. Brown J, Stonelake S, Anderson W, et al. Medical student perception of anatomage - a 3D interactive anatomy dissection table. Int J Surg. 2015;23:S17-S18. doi:10.1016/j.ijsu.2015.07.053

25. Gross M, Masters C. Virtual dissection: using active learning with the anatomage table to enhance student learning. FASEB J. 2017;31(S1): lb9-lb9. doi:10.1096/fasebj.31.1_supplement.lb9

26. Tenaw B. Teaching gross anatomy: anatomage table as an innovative line of attack. Int J Anat Var. 2020;13(1).

27. Adamczyk C, Holzer M, Putz R, Fischer MR. Student learning preferences and the impact of a multimedia learning tool in the dissection course at the University of Munich. Ann Anat. 2009;191 (4):339-348. doi:10.1016/j.aanat.2009.03.003

28. Allen LK, Bhattacharyya S, Wilson TD. Development of an interactive anatomical three-dimensional eye model. Anat Sci Educ. 2015;8(3):275-282. doi:10.1002/ase.1487

29. Fyfe G, Fyfe S, Dye D, Radley-Crabb H. Use of anatomage tables in a large first-year core unit. In: Carter H, Gosper M, Hedberg J, editors. Proceedings of the Electric Dreams 30th ascilite Conference; Sydney, NSW: Macquarie University. 2013:298-302.

30. Custer T, Michael K The utilization of the anatomage virtual dissection table in the education of imaging science students. Posters and Presentations: Medical Imaging \& Therapeutic Sciences; July 1, 2015. Available from: https://digitalcommons.unmc.edu/cahp_mits pres/6. Accessed May 24, 2021. 


\section{Publish your work in this journal}

Advances in Medical Education and Practice is an international, peerreviewed, open access journal that aims to present and publish research on Medical Education covering medical, dental, nursing and allied health care professional education. The journal covers undergraduate education, postgraduate training and continuing medical education including emerging trends and innovative models linking education, research, and health care services. The manuscript management system is completely online and includes a very quick and fair peer-review system. Visit http://www.dovepress.com/testimonials.php to read real quotes from published authors.

Submit your manuscript here: http://www.dovepress.com/advances-in-medical-education-and-practice-journal 